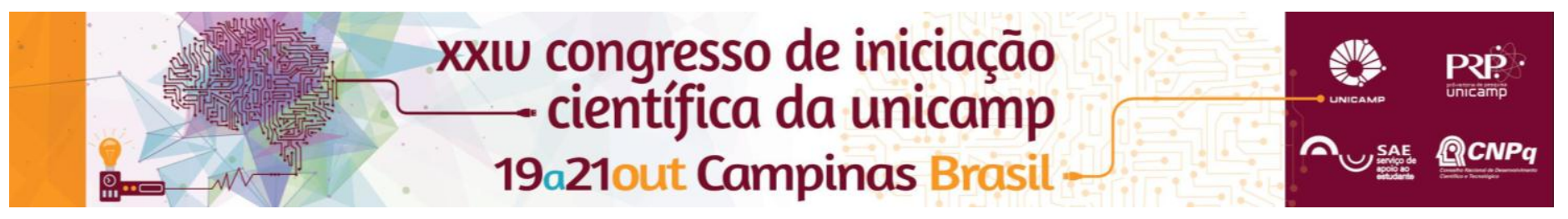

\title{
Qualidade física do solo em terras pretas arqueológicas transformadas e naturais
}

\author{
lago Peres dos Santos*, Marcelo Dayron Rodrigues Soares, Zigomar Menezes de SouzaSouza
}

\section{Resumo}

As Terras Pretas Arqueológicas (TPA's) surgiram, não intencionalmente, pelo homem pré-colombiano. Nas TPA's encontram-se artigos cerâmicos e solos muito férteis, devido à decomposi-ção da matéria orgânica deixada pelos ancestrais. O presente trabalho teve por objetivo avaliar a variabilidade espacial da densidade do solo, porosidade do solo e resistência do solo à penetração em TPA's.

Palavras-chave: Manejo do solo, Física do solo e Geoestatística.

\section{Introdução}

As Terras Pretas Arqueológicas (TPA's) ou Terras Pretas de Índio compreendem solos caracteristicamente de coloração escura e fragmentos de cerâmica e/ou líticos incorporados aos seus horizontes mais superficiais (KAMPF; KERN, 2005) caracterizadas por apresentarem elevada fertilidade natural que é fortemente relacionada com as características moleculares da fração alcalino-solúvel do carbono orgânico e substâncias húmicas. O presente trabalho teve por objetivo avaliar a variabilidade espacial da densidade do solo, porosidade do solo e resistência do solo à penetração em TPA's.

\section{Resultados e Discussão}

Os valores de média e da mediana para todas as variáveis foram similares (Tabela 1). Os valores do coeficiente de variação de modo geral foram baixos, mostrando um grupo de dados mais homogêneos. Notase que os valores de densidade do solo e resistência do solo à penetração na área de pastagem foram maiores que na mata nativa, provavelmente devido ao pisoteio animal, os valores dessas variáveis foram mais elevados.

Tabela 1. Densidade do solo $\left(\mathrm{kg} \mathrm{m}^{-3}\right)$, porosidade total (\%), resistência do solo à penetração (MPa) determinadas nas áreas de terra preta arqueológica sob mata nativa e pastagem nas camadas de 0,00-0,10, $0,10-0,20$ e $0,20-0,40 \mathrm{~m}$.

\begin{tabular}{|c|c|c|c|c|c|c|c|}
\hline Atributos & Estatistca & $0,0-0,10$ & $0,10-0,20$ & $0,20-0,40$ & $0,0-0,10$ & $0,10-0,20$ & $0,20-0,40$ \\
\hline & & \multicolumn{3}{|c|}{ Mata Nativa } & \multicolumn{3}{|c|}{ Pastagem } \\
\hline \multirow{4}{*}{$\mathrm{D} s\left(\mathrm{~kg} \mathrm{~cm}^{2}\right)$} & Média & 0,90 & 0,95 & 0,98 & 1,29 & 1,17 & 1,16 \\
\hline & Mediana & 0,89 & 0,96 & 0,97 & 1,30 & 1,16 & 1,18 \\
\hline & $\mathrm{CV}$ & 11,76 & 9,34 & 13,46 & 9,03 & 9,29 & 7,84 \\
\hline & $d^{*}$ & $0,09^{*}$ & $0,10^{\circ}$ & $0,09^{\circ}$ & $0,15^{*}$ & $0,15^{*}$ & $0,14^{*}$ \\
\hline \multirow[b]{2}{*}{ PT $(\%)$} & Média & 69,00 & 65,75 & 63,63 & 39,00 & 46,00 & 47,00 \\
\hline & $\begin{array}{c}\text { Mediana } \\
\mathrm{CV}\end{array}$ & $\begin{array}{l}68,54 \\
6,91\end{array}$ & $\begin{array}{c}66,42 \\
6,56\end{array}$ & $\begin{array}{l}63,95 \\
6,46\end{array}$ & $\begin{array}{c}38,00 \\
8,72\end{array}$ & $\begin{array}{l}45,00 \\
9,06\end{array}$ & $\begin{array}{l}46,00 \\
7,00\end{array}$ \\
\hline \multirow{5}{*}{$\mathrm{RP}(\mathrm{MPa})$} & $d^{*}$ & $0,08^{*}$ & $0,08^{\circ}$ & $0,07^{*}$ & $0,08^{*}$ & $0,15^{*}$ & $0,15^{\circ}$ \\
\hline & Média & 0,89 & 0,91 & 1,11 & 2,10 & 0,78 & 0,57 \\
\hline & Mediana & 0,84 & 0,85 & 1,10 & 2,08 & 0,75 & 0,51 \\
\hline & $\mathrm{CV}$ & 32,63 & 30,0 & 41,62 & 26,29 & 33,85 & 38,07 \\
\hline & $d^{*}$ & $0,08^{*}$ & $0,07^{*}$ & 0,07 & 0,10 & $0,02^{\mathrm{ma}}$ & 0,012 \\
\hline
\end{tabular}

$\mathrm{RP}=$ resistência do solo à penetração; $\mathrm{Ds}=$ densidade do solo; $\mathrm{PT}=$ porosidade total. $\mathrm{CV}=$ coeficiente de variação; $d={ }^{*}$ significativo a $5 \%$ de probabilidade pelo teste Kolmogorov-Smirnov.

A densidade do solo na área de mata apresentou maior coeficiente de variação (Tabela 2). Por outro lado, este mesmo atributo na área de pastagem, apresentou o maior valor da validação cruzada.

Tabela 2. Parâmetros geoestatísticos dos atributos físicos do solo em terras pretas arqueológica sob manejos em diferentes camadas.

\begin{tabular}{|c|c|c|c|c|c|c|c|}
\hline Atributos & $\begin{array}{c}\text { Parámetros } \\
\text { Geoestatistico }\end{array}$ & $0,0-0,10$ & $0,10-0,20$ & $0,20-0,40$ & $0,0-0,10$ & $0,10-0,20$ & $0,20-0,40$ \\
\hline & & & Mata Nativa & & & Pastagem & \\
\hline & Modelo & Exp. & Exp. & Exp. & Exp. & Exp. & Exp. \\
\hline \multirow[t]{3}{*}{ Ds } & $\mathrm{R}^{2}$ & 0,94 & 0,97 & 0,95 & 0,91 & 0,82 & 0,87 \\
\hline & $\begin{array}{l}\text { GDE } \\
V C\end{array}$ & $\begin{array}{c}19 \\
0,70\end{array}$ & $\begin{array}{c}10 \\
0.75\end{array}$ & $\begin{array}{c}16 \\
0,71\end{array}$ & $\begin{array}{c}1 \\
0.98\end{array}$ & $\begin{array}{c}12 \\
0.99\end{array}$ & $\begin{array}{c}10 \\
0,89\end{array}$ \\
\hline & Modelo & Exp. & Esf. & Esf. & Esf. & Exp. & Exp. \\
\hline \multirow[t]{3}{*}{ PT } & $\mathrm{R}^{2}$ & 0,80 & 0,95 & 0,93 & 0,82 & 0,82 & 0,82 \\
\hline & GDE & 9 & 38 & 10 & 4 & 12 & 13 \\
\hline & $\begin{array}{l}\text { VC } \\
\text { Modelo }\end{array}$ & $\begin{array}{l}0,71 \\
\text { Exp }\end{array}$ & $\begin{array}{l}0,70 \\
\text { Exp }\end{array}$ & $\begin{array}{l}0,73 \\
\text { Esf. }\end{array}$ & $\begin{array}{l}0,90 \\
\text { Exp }\end{array}$ & $\begin{array}{l}0,83 \\
\text { Exp }\end{array}$ & $\begin{array}{l}0,86 \\
\text { Esf. }\end{array}$ \\
\hline \multirow[t]{3}{*}{$R P$} & $\mathrm{R}^{2}$ & 0,90 & 0,90 & 0,90 & 0,94 & 0,74 & 0,92 \\
\hline & GDE & 12 & 11 & 40 & 11 & 57 & 50 \\
\hline & vC & 0,89 & 0,87 & 0,89 & 0,80 & 0,73 & 0,74 \\
\hline
\end{tabular}

Exp = exponencial; Esf = esférico; $\mathrm{R}^{2}=$ coeficiente de determinação; VC = validação cruzada; GDE = grau de dependência espacial.

Os resultados da análise do semivariograma mostraram que todos os atributos estudados apresentaram dependência espacial (Tabela 2). Os modelos dos semivariogramas ajustados foram 0 esférico e o exponencial. Estes modelos são considerados transitivos, pois alcançam um valor denominado patamar e, a distância em que atingem este patamar é chamado de alcance. Os modelos esférico e exponencial são os modelos mais frequentes e que ajustam aos semivariogramas dos atributos do solo.

\section{Conclusões}

Todos os atributos apresentaram estrutura de dependência espacial.

Os valores de densidade do solo e resistência do solo à penetração foram mais elevados no manejo de pastagem, quando comparado ao de mata nativa.

Os ajustes dos valores da validação cruzada e coeficiente de determinação foram acima de $70 \%$.

KÄMPF, N.; KERN, D.C. Antigos assentamentos indígenas na formação de solos com Terra Preta Arqueológicas na Região de Oriximiná, Pará. Revista Brasileira Ciência do Solo, Viçosa, v.13, p.219-225, 1989. 